self-induction and capacity the testing instrument is tuned to resonate with the vibration to be measured. The right point is shown, for instance, in the Fleming cymometer, by the point of maximum glow in a vacuum tube. From the known capacity and selfinduction of the instrument, at this point, its oscillation constant can be calculated, and, therefrom, the wavelength obtained. For a description of these very interesting instruments and other valuable information we must, however, refer the reader to the book itself.

\section{C. G.}

\section{THE SENSES OF INSECTS.}

The Senses of Insects. By Auguste Forel. Translated by Macleod Yearsley. Pp. xvi+324; two plates. (London: Methuen and Co., n.d.) Price ros. $6 d$. net.

COMPARATIVE psychology as a science is beset with more difficulties than most of its kindred natural sciences. One of the greatest of these difficulties is that man, a creature gifted with the most highly developed intelligence, endeavours to interpret and explain the actions of the lesser intellectually en. dowed members of the animal kingdom from their standpoint. However much he may endeavour to avoid assuming an anthropocentric attitude, he must invariably find himself seated again on his pedestal of intellectual preeminence. He cannot avoid it; it is the only criterion he possesses. This difficulty is never more apparent than when an effort is made to study the manifold activities of that most active of the animal groups, the insects, and especially those families in which social habits have attained such a high state of perfection. In the study of the senses of insects we are necessarily compelled to form inferences from our own sensory experiences, and the result is that we not only cannot obtain an adequate conception of their ordinary sensory powers, but are completely baffled by many organs of an undoubted sensory nature.

Dr. Forel's work on this subject is not so well known in this country as it deserves to be. This, no doubt, is due largely to the fact that most of it has been published in rather out-of-the-way journals. Those students whose interest in the subject has been stimulated by Lord Avebury's work will be grateful to Mr. Yearsley for having performed this "labour of love," as he describes his translation.

The direct translation and publication in toto of a series of writings of such a nature, however, has its disadvantages. The present volume contains writings which date from the year 1878 to 1906 . We have, therefore, not only the author's natural changes of opinion, but also mistakes, in fact, which have been brought about by the gradual growth of entomological inquiry. For example, in the section on hearing, the author states that "only crickets and several other Orthoptera appear to perceive sounds," which, in the light of more recent work of Mayer, Child, and others on the acoustics of certain nematocerous Diptera, is not quite correct. Nor does the author devote sufficient attention to the thoracic and crural tympanal organs of the Orthoptera, so well described by Graber, and of insects of other orders. To a present-day student of entomology a book on the senses of insects is incomplete without fuller reference to the morphological aspect of the subject, notwithstanding the lack of experimental studies. The author truly says, "for the human and animal brain, as well as for its functions, it demands that we shall use anatomical, physiological, biological, and psychological methods." The presence in insects of many problematic organs, which from their histological structure and connections appear to be of a sensory nature, such as, for example, those associated with the halteres of Diptera and the various chordonotal organs which have been described, does not detract from the difficulties which confront the student of these problems. The author pays little attention to these problematic organs, and, in view of the absence of experimental work on them, he is no doubt wise in not discussing them in the absence of facts, as some writers on the subject are accustomed to do. Where he treats with the senses of sight and smell he is more at home; his experiments are very interesting and valuable, and some of his results conclusive; it is in the description of these experiments that the value of the book lies rather than in his, in places, extensive polemical references to some of the work of others.

The last chapter, on judgment, mind, and reflexes, is one of the most interesting. The author is of the opinion that plastic reaction is primary, and that instinctive or automatic activity which predominates in the insects is secondary. He does not think that instinct can proceed from inherited habits, but that the automatism of all nervous activity, whether by selective heredity or individual habit, is a secondary phenomenon derived from primitively plastic habits, and in support of this he refers to the plastic origin of the slave-making instinct of the species of Formica.

We venture to think that the book would have been improved had the translator dispensed with a detailed account of the author's earlier work, the essentials of which might have been incorporated in the account of his later work; or had the author brought these earlier writings up to date with regard to our present knowledge of the morphological aspect of the problem, its value to the general reader would have been considerably enhanced thereby. With the exception of sub-œsophageal ganglion (p. 5) where supraœsophageal is surely intended, and Chalcidites (p. I40) for Chalcidides, there are few mistakes of nomenclature in the work. C. Gordon Hewitr.

\section{FORESHORE PROTECTION.}

Coast Erosion and Foreshore Protection. By John S. Owens and Gerald O. Case. Pp. 148 . (London: The St. Bride's Press, n.d.) Price $7 s .6 d$. net. THIS book consists principally of a reprint of papers on foreshore protection read before various societies, and of articles contributed to magazines.

Although it does not deal in such a comprehensive way with the subject of coast destruction and protection as the book on "The Sea Coast" published

NO. 20,30 , VOL. $\approx 81$ 